\title{
Water Soaking and Re-Drying Effect on Mechanical and Wear Properties of Nanoclay-Polyester Nanocomposites
}

\author{
Achutha Kinia, Manjunath Shettar ${ }^{a *}$ (1), Suhas Kowshik ${ }^{a}$, Nikhil R ${ }^{b}$, Ganesh Chate ${ }^{c}$ [] \\ ${ }^{a}$ Manipal Academy of Higher Education, Manipal Institute of Technology, Department of Mechanical \\ and Manufacturing Engineering, 576104, Manipal, Karnataka, India. \\ ${ }^{b}$ Reva University, School of Mechanical Engineering, 560064, Bangalore, Karnataka, India. \\ ${ }^{c}$ KLS Gogte Institute of Technology, Department of Mechanical Engineering, 590008, Belagavi, \\ Karnataka, India.
}

Received: September 20, 2021; Revised: November 20, 2021; Accepted: December 29, 2021

\begin{abstract}
This research aims to investigate the influence of water soaking and re-drying on the mechanical and wear properties of nanoclay-polyester nanocomposites (NPNCs). The nanoclay addition significantly enhances the mechanical properties of NPNCs in as-made, water-soaked and re-dried conditions. Also, the addition of nanoclay decreased the percentage of reduction in mechanical properties under water-soaking condition. Re-drying recovers more than $90 \%$ in values of mechanical properties compared to original values. In contrast, the addition of nanoclay reduces the mass loss (wear test) of specimens in all three conditions. Re-dried specimens have lesser mass loss than water-soaked specimens and greater mass loss than as-made specimens. SEM images illustrate that the absorbed water can alter the fracture and worn-out surface by swelling and plasticization. Also, SEM images reveal that re-drying can reverse the effect of swelling and plasticization of the specimens.
\end{abstract}

Keywords: Nanoclay, Polyester, Water-soaking, Re-drying, Mechanical properties, Mass loss.

\section{Introduction}

"Unsaturated polyester resins" (UPRs) are frequently utilized as thermoset polymers because of their low cost and ease of processing for composite fabrications. UPRs are made up of glycol and unsaturated dibasic acid that have been condensed. Automobiles, water tanks, packaging, and construction materials have all employed UPRs. The addition of inorganic additives to UPR improves its thermal and mechanical characteristics ${ }^{1-3}$. The interfacial adhesion among the polymer matrix and the reinforcing material, generally impacted by a relative incompatibility amongst the organic and inorganic phases, and is linked to their efficacy ${ }^{4}$.

Polymers are susceptible to environmental degradation triggered by temperature, humidity, varying loads, and their combinations ${ }^{5,6}$. Most of the polymer composites engross moisture, and the molecules of water can function as a plasticizer. Therefore, the behavior of polymers in harsh environmental conditions should be understood throughout their service life. Even though several studies on the water absorption of polymer composite materials are in the literature, understanding the water absorption mechanism is extremely difficult. Saharudin et al. ${ }^{7}$, investigated the effect of short-term water exposure on the polyesterbased nanocomposite. It has been demonstrated that the polyester matrix is susceptible to water exposure, and the addition of nano-reinforcements has reduced the effect of water exposure. Alamri and $\mathrm{Low}^{8}$ discovered that water absorption reduced the flexural strength and modulus of

*e-mail: manjunath.shettar@manipal.edu epoxy-based nanocomposites. They conclude that the addition of nanofillers improved the flexural properties of nanocomposites and reduced the effect of water absorption on the epoxy. Temperature, reinforcement weight percentage and its architecture, area of exposed surfaces, degree of cross-linking, and crystallinity are factors well-known to influence how composite materials absorb water'.

In polymer nanocomposites, nanoclay is one of the most often studied and used nanoparticles. Because of its convenience to use, environmental advantages, and precise chemistry, nanoclay has risen to prominence among nanoparticles ${ }^{10}$. Nanoclay has superior modulus, inexpensiveness, low density, and larger surface area. A modest amount of nanoclay, generally less than $5 \mathrm{wt} . \%$, can improve a wide range of properties $^{11,12}$. The introduction of nanoclay in polymers potentially improves fracture toughness while sustaining other characteristics, including strength, modulus, thermal stability, flame retardancy, and glass transition temperature ${ }^{13}$. Many investigations have been done on nanoclay-polyester nanocomposites, and the researchers reported that adding nanoclay enhances the properties of polyester resin ${ }^{3,14,15}$.

The present study investigates the effect of water soaking and re-drying conditions on mechanical and wear properties of nanoclay-polyester nanocomposites (NPNCs). It also targets the influence of different nanoclay weight percentages on water absorption, tensile and flexural strengths, and wear property (mass loss) of polyester under water aging and drying conditions. In addition, fracture surfaces under tensile load and worn-out surfaces are investigated in order to establish the causes of specimen failure. 
The knowledge of the effects of water soaking and redrying conditions on mechanical and wear properties is not certainly observed in the literature on polyester nanocomposites, including a varying weight percentage of nanoclay. This looks critical in expanding the range of applications for these nanocomposites, particularly in automobile, marine, construction, and domestic sectors. The aim of undertaking this work is to study whether the addition of nanoclay can reduce the water degradation effect caused by water uptake, and re-drying the water soaked specimens can recover the properties of polymer composites.

\section{Investigational Procedures}

\subsection{Materials and methods to prepare specimens}

Nanoclay ("Surface modified contains 15-35 wt. $\%$ octadecylamine, $0.5-5 \mathrm{wt}$. \% aminopropyltriethoxysilane") is used as a reinforcement and purchased from Sigma Aldrich. Nanoclay has a sheet-like structure (Figure 1) with a density of 0.2 to $0.5 \mathrm{~g} / \mathrm{cm}^{3}$. Each nanoclay sheet has lateral dimensions of 200-600 nanometers and is just a few nanometers thick ${ }^{16}$. Nanoclay has a higher modulus than the matrix, barrier, chemical resistance, and flame retardancy properties. Nanoclay is a potential reinforcement for polymers due to its sheet shape and high aspect ratio.
Polyester resin and curing agents as cobalt accelerator and MEKP catalyst ("mixing ratio $1 \mathrm{~kg}: 12 \mathrm{ml}$ : $15 \mathrm{ml}$ ") are used as the matrix material. Using different nanoclay weight percentages ( 0 (pure polyester), $2 \& 4$ ), a total of 3 sets of specimens are produced. Nanoclay and polyester are mixed together using mechanical stirring for 2 hours. In order to obtain adequate mixing of nanoclay with polyester, sonication is used for 0.5 hours after mechanical stirring. The cobalt accelerator and MEKP catalyst are also thoroughly mixed into the nanoclay-polyester mixture before being poured into the molds. The specimen molds are made according to ASTM standards D638-14 ${ }^{14,17}$ (dumbbell-like shape) and D790-10 $0^{14,18}$ (a rectangular shape with $140 \mathrm{~mm} \times 15 \mathrm{~mm} \times 3 \mathrm{~mm}$ dimensions). The prepared specimens are shown in the Figure 2. Emery paper is used to smooth the rough surfaces of demolded specimens.

\subsection{Water soaking and re-drying conditions}

The prepared specimens are kept in the tap water at room temperature. The specimens are weighed weekly during the water soaking tests (ASTM D570-98 standard ${ }^{14,19}$ ) using a digital weighing apparatus to find the difference in weight and water uptake percentage. The specimens are kept in water till the saturation point and followed with oven re-drying at $110^{\circ} \mathrm{C}$ for 24 hours.

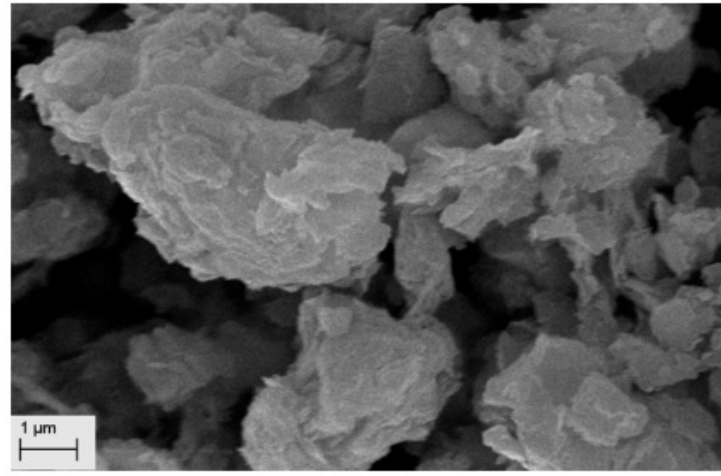

(a)

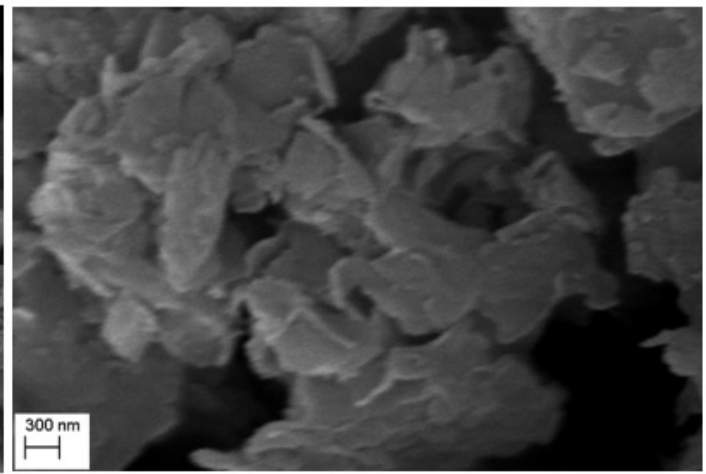

(b)

Figure 1. SEM images of nanoclay (a) 20K X and (b) 40K X magnification.

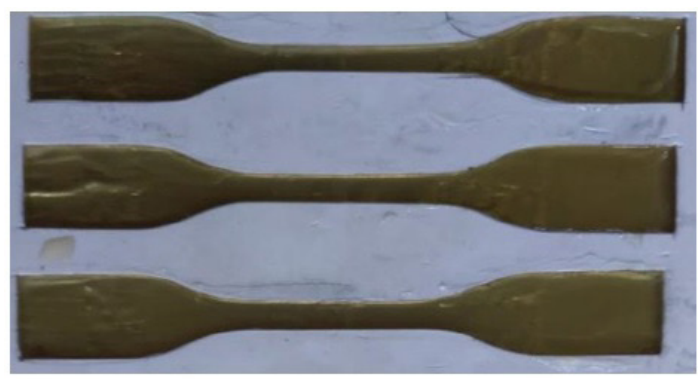

(a)

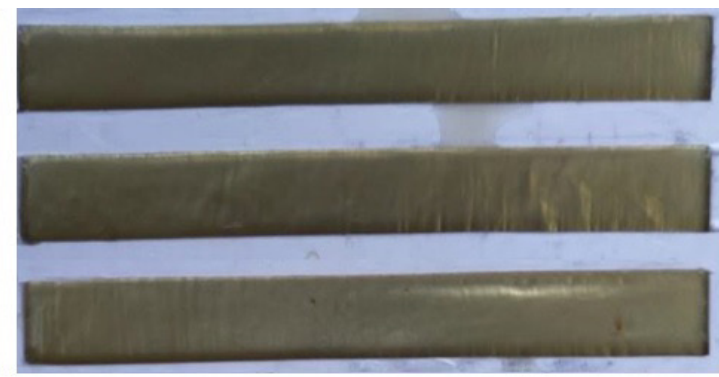

(b)

Figure 2. Prepared specimens for (a) tensile test (b) flexural test. 
The water uptake $(\%)$ is determined using the following equation:

Water uptake $(\%)=(W s-W a) \times 100 / W a$

Where, Ws - Weight after soak; Wa - Weight of specimen before water soak

\subsection{Mechanical testing}

Tensile testing is performed in accordance with ASTM D638-14 ${ }^{14,17}$ using a "Universal Testing Machine". Tensile test specimens are produced in a "dumbbell-like" form. For each set (i.e., 0, 2, and 4 wt.\%) and condition (As-made, water-soaked, and re-dried) mimimus 5 spcimens each are tested. The crosshead motion is kept at a constant speed of $5.0 \mathrm{~mm} / \mathrm{min}$ during the test.

Similar to tensile testing, the ASTM D790-10 standard $^{14}$, ${ }^{18}$ is used to conduct the 3 -point flexural test. The span length in flexural testing is fixed at $48 \mathrm{~mm}$, and the speed for test is kept constant at $1.28 \mathrm{~mm} / \mathrm{min}$.

\subsection{Wear testing}

The ASTM G99-17 standard $^{14,20}$ is used to conduct wear-tests on NPNCs for each set (i.e., 0, 2, and 4 wt.\%) and condition (As-made, water-soaked, and re-dried) using a pin-on-disc device. A hardened steel disc having a minimum surface roughness $(\mathrm{Ra}=5)$ is utilized. With the use of a fixture, the specimen is kept vertical to the revolving disc. For wear test, speed (200 rpm), load $(2 \mathrm{~kg})$, time (10 mins), and track diameter $(80 \mathrm{~mm})$ are kept constant to investigate the influence of varying wt. \% nanoclay and different conditions on the mass loss of NPNCs.

\subsection{SEM analysis}

A "Scanning Electron Microscope (SEM); Model: EVO18, ZEISS" is used to capture the morphology of the fractured and worn-out surfaces of the tested NPNC specimens. The SEM images are utilised to explore the causes for the specimen failure.

\section{Results}

\subsection{Water uptake}

The total water uptake ( $\%)$ of NPNCs reduces progressively as nanoclay wt.\% increases, as illustrated in Table 1 . It is also evident that pure polyester and NPNC specimens have attained saturation limit for water uptake between 77 to 84 days. At the saturation level, the addition of 2 and 4 wt. $\%$ of nanoclay diminishes total water uptake (\%) to 1.43 and $1.34 \%$, respectively, compared to pure polyester, i.e., $1.51 \%$. Pure polyester absorbs more water because of the presence of "hydrolysable ester groups" in the molecular structures $^{21}$. The inclusion of nanoclay into the polyester network decreases the mean free route for water molecules to cross, resulting in decreased water uptake (Figure 3). The increased aspect ratio of nanoclay creates tortuous routes for water molecules, which is the main cause for the improved resistance to water uptake ${ }^{3}$.
Table 1. Water uptake (\%) by pure polyester and NPNCs.

\begin{tabular}{cccc}
\hline \multicolumn{4}{c}{ Water uptake (\%) by pure polyester and NPNCs } \\
\hline Days & Pure polyester & 2 wt.\% NPNC & 4 wt.\% NPNC \\
\hline 7 & 0.59 & 0.53 & 0.48 \\
\hline 14 & 0.92 & 0.83 & 0.74 \\
\hline 21 & 1.1 & 1 & 0.89 \\
\hline 28 & 1.24 & 1.11 & 1.03 \\
\hline 35 & 1.31 & 1.24 & 1.16 \\
\hline 42 & 1.4 & 1.32 & 1.23 \\
\hline 49 & 1.44 & 1.36 & 1.28 \\
\hline 56 & 1.46 & 1.38 & 1.29 \\
\hline 63 & 1.48 & 1.4 & 1.31 \\
\hline 70 & 1.49 & 1.41 & 1.33 \\
\hline 77 & 1.51 & 1.43 & 1.34 \\
\hline 84 & 1.51 & 1.43 & 1.34 \\
\hline
\end{tabular}

\subsection{Mechanical properties}

\subsubsection{Tensile properties}

Figure 4 depicts the traditional stress vs. strain behavior under tensile load. When the tensile stress reaches the absolute limit, all specimens fail immediately. However, before reaching maximum stress, the stress vs. strain curves exhibits significant non-linearity. In comparison to pure polyester, the nanoclay addition improves the stress value of NPNC before failure and reduces the strain to fail under tensile load. The strain value of NPNCs is reduced due to the addition of nanoclay because of increased stiffness of the $\mathrm{NPNCs}^{1,22}$.

Stress vs. strain curves of pure polyester and NPNCs under water soaking conditions show a decrease in initial slope, ultimate tensile stress, and increase in failure strain compared to as-made conditions. It can be noted that NPNCs with nanoclay are less influenced due to the excellent barrier properties of nanoclay compared to pure polyester concerning tensile stress ${ }^{3}$. Compared to water-soaked conditions, stress vs. strain curves of re-dried pure polyester and NPNCs show a recovered ultimate tensile stress.

As presented in Table 2, nanoclay addition enhances polyester resin's tensile strength and modulus to $35.3 \mathrm{MPa}$ and $1.1 \mathrm{GPa}$ at $2 \mathrm{wt} . \%$ of nanoclay and $34.2 \mathrm{MPa}$ and $1.2 \mathrm{GPa}$ at 4 wt. $\%$ of nanoclay, respectively. The improved tensile properties at 2 wt.\% NPNC are due to improved nanoclay platelet dispersion in the polyester resin and bonding among nanoclay and polyester chains, leading to enhanced load transmission between nanoclay and matrix ${ }^{23}$. At 4 wt. $\%$ nanoclay, the tensile strength of the NPNC slightly decreases compared to $2 \mathrm{wt} . \%$ of nanoclay. But, in contrast, the tensile modulus of NPNCs increased due to the imparting effect of filler reinforcements, which are rigid than polymer matrix.

As described in Table 2, the water soaking condition has a considerable negative influence on the tensile properties of pure polyester and NPNCs. The tensile strength and modulus of pure polyester under water-soaked condition are decreased by 20 and $17 \%$, respectively; due to engrossed water that act as a plasticizer for polymers in general. The tensile strength and modulus of NPNCs are decreased by 16 and $15 \%$ at 2 wt. $\%$ nanoclay and 12 and $12 \%$ at $4 \mathrm{wt} \% \%$ nanoclay, respectively. 
Table 2. Tensile properties of pure polyester and NPNCs.

\begin{tabular}{lccccccccc}
\hline & \multicolumn{2}{c}{ As-made } & & \multicolumn{2}{c}{ Water-soaked } & & \multicolumn{3}{c}{ Re-dried } \\
\cline { 2 - 3 } & $\begin{array}{c}\text { Tensile Stress } \\
(\mathrm{MPa})\end{array}$ & $\begin{array}{c}\text { Tensile Modulus } \\
(\mathrm{GPa})\end{array}$ & & $\begin{array}{c}\text { Tensile Stress } \\
(\mathrm{MPa})\end{array}$ & $\begin{array}{c}\text { Tensile Modulus } \\
(\mathrm{GPa})\end{array}$ & & $\begin{array}{c}\text { Tensile Stress } \\
(\mathrm{MPa})\end{array}$ & $\begin{array}{c}\text { Tensile Modulus } \\
(\mathrm{GPa})\end{array}$ \\
\hline Pure polyester & 30.5 & 0.9 & & 24.4 & 0.75 & & 28.0 & 0.84 \\
\hline 2 wt.\% NPNC & 35.3 & 1.1 & 29.7 & 0.93 & 32.9 & 1.04 \\
\hline 4 wt.\% NPNC & 34.2 & 1.2 & 30.0 & 1.06 & 32.2 & 1.14 \\
\hline
\end{tabular}

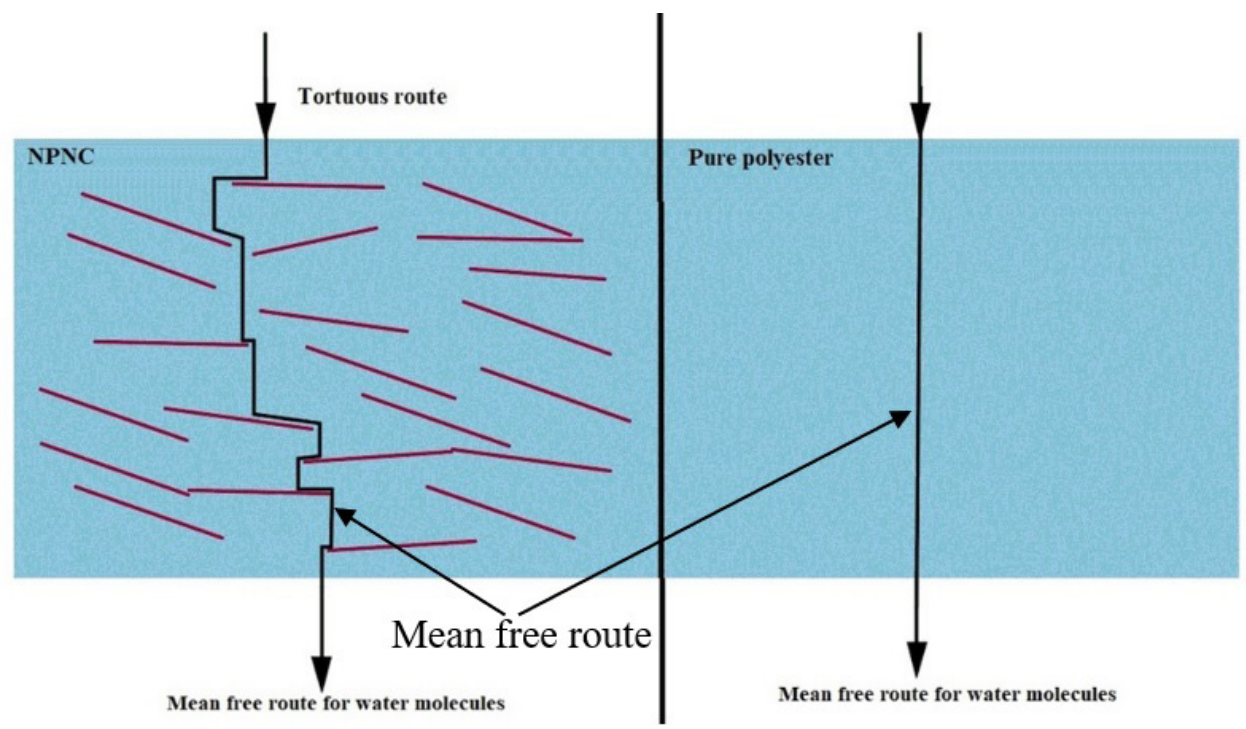

Figure 3. Movement of water molecules.

The effect of nanoclay addition in improving the resistance to plasticization is evident by the lesser percentage of reduction in the tensile properties ${ }^{24}$. Also, nanoclay creates "tortuous routes" 25 for water molecules to enter NPNCs, delaying the overall effect of the water soaking condition. Furthermore, compared to pure polyester, the nanoclay's greater aspect ratio provides resistance to polymer chain agility in water absorbed polymers, leading to reduced tensile strength drop.

As depicted in Table 2, re-dried pure polyester and NPNC specimens have greater tensile properties than the water-soaked specimens. However, compared to as-made specimens, the tensile properties of re-dried specimens are still lower. The tensile properties of water-soaked specimens are partially recovered in re-dried specimens because most of the water is removed from the polyester network, and the plasticization impact is minimal ${ }^{26}$. Tensile properties of pure polyester and NPNCs are restored to more than $90 \%$ of its original value (as-made specimens). The reversible effects of the absorbed water, such as plasticization, may be attributed to this tensile properties recovery. Still, the unrecovered part of the tensile properties can be attributed to the permanent damages imposed by water.

\subsubsection{SEM analysis}

Figure 5 illustrates the fractured surface morphology for pure polyester under as-made, water-soaked, and re-dried conditions. The pure polyester (Figure 5a) displays a smooth, featureless surface, representing rapid crack propagation and

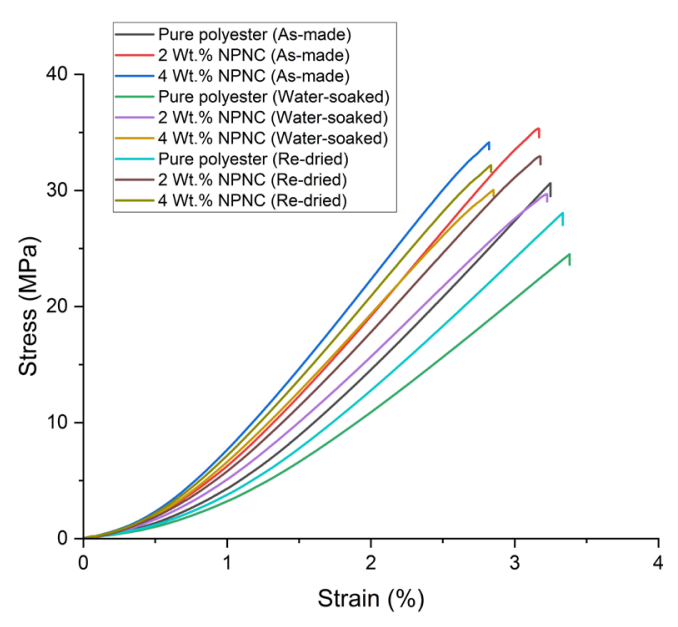

Figure 4. Tensile stress vs. strain curves.

lower fracture toughness. According to SEM image (Figure 6a), the fractured surface morphology becomes rougher with the addition of nanoclay. The presence of nanoclay platelets ahead of crack pathways, which encourage the development of many microcracks, is most likely to be responsible for the rough fractured surface of NPNC. The crack propagation path is pushed to become convoluted, resulting in a larger fracture surface area and higher fracture toughness ${ }^{13}$. The nanoclay 


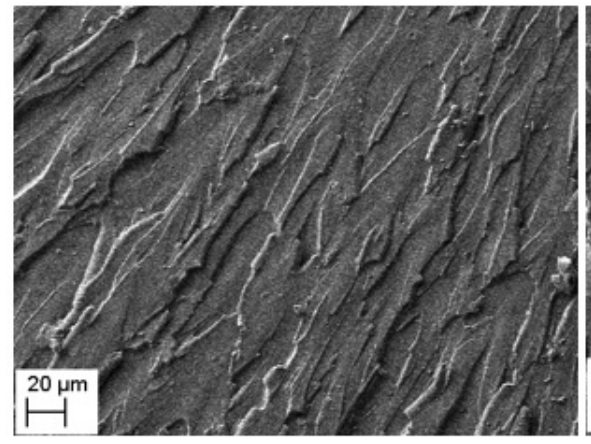

(a)

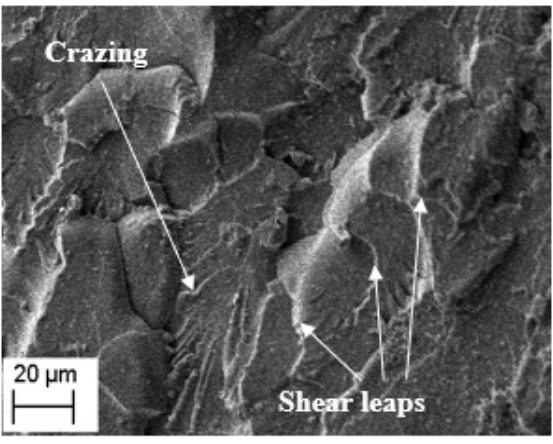

(b)

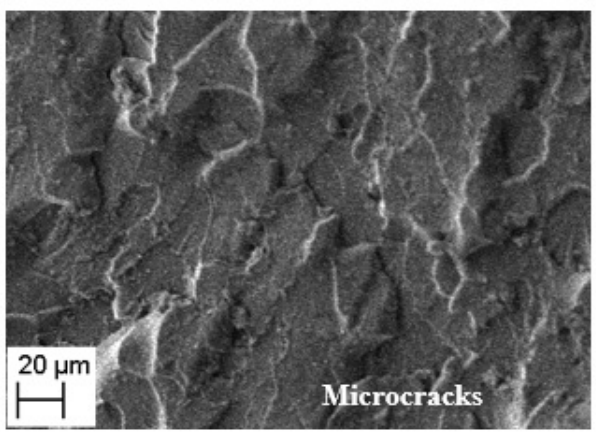

(c)

Figure 5. SEM images of the fracture surface of pure polyester under different conditions (a) As-made (b) Water-soaked (c) Re-dried.

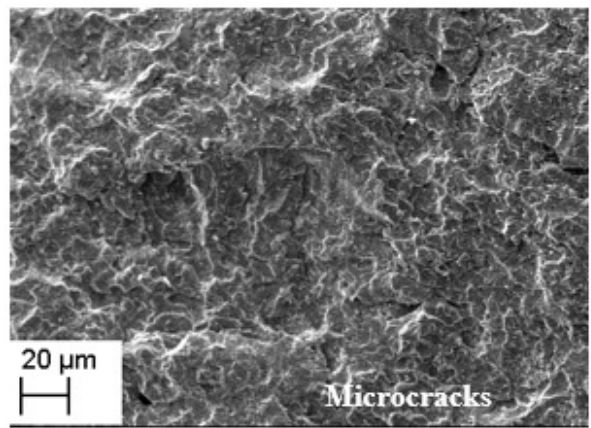

(a)

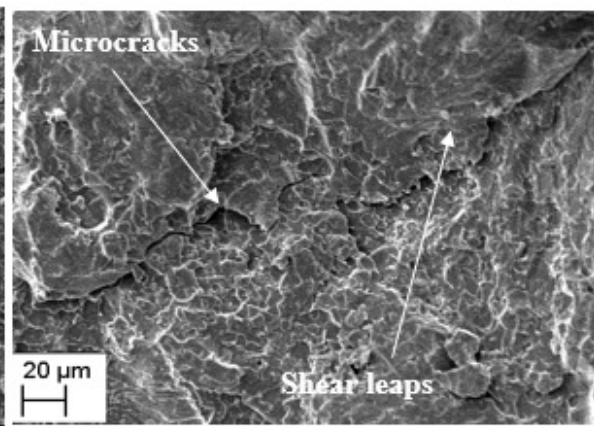

(b)

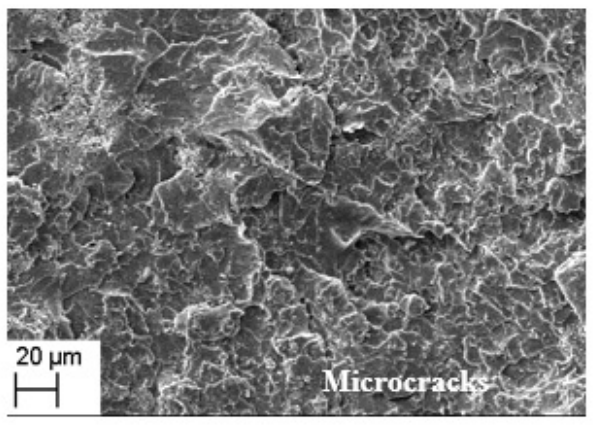

(c)

Figure 6. SEM images of the fracture surface of NPNC under different conditions (a) As-made (b) Water-soaked (c) Re-dried. 
platelets act as a barrier against fracture propagation, because of which the tensile strength of NPNC has increased, as presented in Table 2 .

In water-soaking condition, for pure polyester specimen (Figure 5b), a complex linkage of micro-cracks on the fracture surface is seen due to absorbed water, boosting craze initiation and propagation in the polyester and promoting the plasticization effect of moisture ${ }^{27}$. Stress is severe enough to induce secondary local cracks at various phases of crack growth, causing the rougher area close to the crack front to develop. Since the crack propagates quickly, the crazes that begun near the crack front do not have enough time to spread. Water-soaked NPNC specimen (Figure 6b) shows the existence of shear leaps and a less rough surface at the fracture surface, suggesting lower fracture toughness than the as-made specimen (Figure 6a). SEM images show that water soaking has a substantial influence on pure polyester when compared to NPNC. This might explain why tensile strength of polyester decreased more significantly than NPNC. The addition of nanoclay to polyester increases cross-linking density and makes water molecule migration more difficult. Nanoclay inclusion minimizes the impact of water-soaking compared to pure polyester, resulting in a smaller percentage drop in tensile strength.

On the fracture surface of re-dried pure polyester and NPNC specimens (Figures 5c and 6c), a network of microcracks and shear leaps can be seen. Re-drying does not fully eliminate the effect of water soaking. The lower fracture toughness of re-dried specimens compared to as-made specimens causes the development of these microcracks. This could explain why tensile strength in re-dried specimens isn't fully recovered.

\subsubsection{Flexural properties}

The typical stress vs. strain curves of pure polyester and NPNCs under flexural load is demonstrated in Figure 7. The slope of the flexural stress vs. strain curves for NPNC is observed to increase compared to pure polyester due to the addition of nanoclay, which strengthens and stiffens the surrounding matrix. Flexural stress vs. strain curves of pure polyester and NPNCs under water soaking conditions show a decrease in maximum flexural stress and increase in flexural strain to failure compared to as-made specimens due to water inside the polyester system elevates the polyester system's ductility. Flexural stress vs. strain curves of re-dried pure polyester and NPNCs show a recovered maximum flexural stress compared to water-soaked conditions.

As presented in Table 3, flexural strength and modulus of NPNCs increase to $57 \mathrm{MPa}$ and $1.3 \mathrm{GPa}$ at 2 wt.\% of nanoclay and $54 \mathrm{MPa}$ and $1.4 \mathrm{GPa}$ at $4 \mathrm{wt} . \%$ of nanoclay, respectively. The enhanced interfacial bonding between nanoclay and matrix is responsible for stress transfer and elastic deformation and NPNC's better flexural properties. Nanoclay strengthens and stiffens the surrounding matrix, which constrains the movement of the polymer chain slipping and creates the matrix less pliable ${ }^{10}$. The polymer chains become more difficult to disentangle and move with the increase in nanoclay weight percentage. The rise in modulus as the nanoclay wt.\% increases is due to this increase in polymer chain restriction.

As stated in Table 3, after water soaking, the flexural properties of pure polyester and NPNC specimens showed degradation compared to as-made specimens. This is largely due to water inside the polyester system, which elevates the polyester system's ductility. The lowest flexural strength (43 $\mathrm{MPa})$ and modulus $(0.83 \mathrm{GPa})$ are observed in pure polyester under water-soaked condition. Water soaking has a lesser effect on NPNCs because of nanoclay, which acts as a barrier to the movement of water molecules ${ }^{27}$. In waterabsorbed NPNC, the higher aspect ratio of the nanoclay platelets offers resistance to polymer chain movement, resulting in reduced flexural properties degradation compared to pure polyester.

Re-dried pure polyester and NPNCs have better flexural properties than water-soaked specimens and lesser flexural properties than as-made specimens. The flexural properties of re-dried specimens are recovered more than $90 \%$ because most of the moisture has been removed, and the plasticization effect is limited ${ }^{28}$.

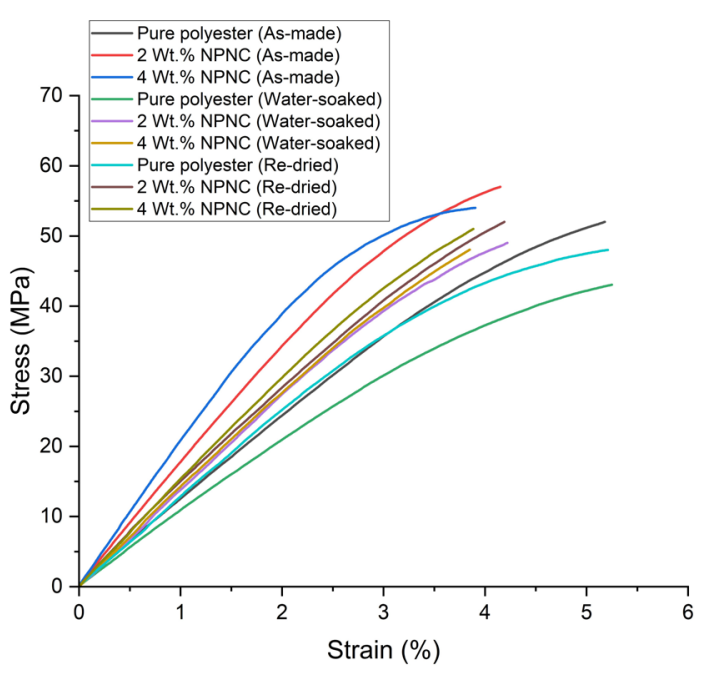

Figure 7. Flexural stress vs. strain curves.

Table 3. Flexural properties of pure polyester and NPNCs.

\begin{tabular}{|c|c|c|c|c|c|c|}
\hline & \multicolumn{2}{|c|}{ As-made } & \multicolumn{2}{|c|}{ Water-soaked } & \multicolumn{2}{|c|}{ Re-dried } \\
\hline & $\begin{array}{c}\text { Flexural Stress } \\
(\mathrm{MPa})\end{array}$ & $\begin{array}{c}\text { Flexural } \\
\text { Modulus (GPa) }\end{array}$ & $\begin{array}{c}\text { Flexural Stress } \\
(\mathrm{MPa})\end{array}$ & $\begin{array}{c}\text { Flexural } \\
\text { Modulus (GPa) }\end{array}$ & $\begin{array}{l}\text { Flexural Stress } \\
(\mathrm{MPa})\end{array}$ & $\begin{array}{c}\text { Flexural } \\
\text { Modulus (GPa) }\end{array}$ \\
\hline Pure polyester & 52 & 1.0 & 43 & 0.83 & 48 & 0.92 \\
\hline 2 wt. $\%$ NPNC & 57 & 1.3 & 49 & 1.18 & 52 & 1.24 \\
\hline 4 wt. $\%$ NPNC & 54 & 1.4 & 48 & 1.23 & 51 & 1.31 \\
\hline
\end{tabular}




\subsection{Wear property}

\subsubsection{Mass loss}

The wear test on pure polyester and NPNCs is carried out to find the mass loss by maintaining other factors constant. Factors viz., speed (200 rpm), load (2 kg), time (10 mins), and track diameter $(80 \mathrm{~mm})$ are kept constant for all the set and conditioned specimens. As presented in Table 4, the nanoclay addition decreases the mass loss of NPNCs under wear test. Because nanoclay has greater strength and hardness, it increases wear resistance (reduced mass loss) ${ }^{14}$. The wear resistance of the NPNC is improved by nanoclay addition, which serves as a solid lubricant and produces a transfer film, reducing friction throughout sliding. Nanoclay also acts as a significant obstacle to large-scale matrix fracture induced by disc.

The wear test has resulted in more mass loss of pure polyester and NPNC specimens under water-soaked condition than as-made condition, as presented in Table 4. Water soaking may result in component geometry change due to swelling. Also, water soaking leads to softening and weakening of hydrogen bonds between polymer chains, which is reflected in the resin plasticization ${ }^{29}$. Swelling and

Table 4. Mass loss under wear test of pure polyester and NPNCs.

\begin{tabular}{lccc}
\hline & \multicolumn{3}{c}{ Mass loss (mg) under wear test } \\
\cline { 2 - 4 } & As-made & Water-soaked & Re-dried \\
\hline Pure polyester & 159 & 175 & 163 \\
\hline 2 wt.\% NPNC & 132 & 141 & 135 \\
\hline 4 wt.\% NPNC & 95 & 103 & 99 \\
\hline
\end{tabular}

plasticization in specimens act as a break instead of bearing and losing the purpose of withstanding the frictional force. The water-soaking has a more severe effect on pure polyester than NPNCs. The addition of nanoclay has significantly diminished the influence of water soaking.

Re-dried pure polyester and NPNCs have lesser mass loss than water-soaked specimens and greater mass loss than as-made specimens. Most of the water is driven out of the system for re-dried specimens, leading to recovery from swelling and plasticization ${ }^{30}$. The effect of water-soaking and re-drying is more in pure polyester than NPNCs.

\subsubsection{SEM Analysis}

The as-made pure polyester worn-out surface (Figure 8a) seems a little rough, further there is certain material pull-out. Through cutting action, the steel disc surface rapidly splits the material from the polymer. The worn-out surface of the as-made NPNC is flatter, indicating no pull-out of material (Figure 9a). The nanoclay takes the brunt of the pressure and reduces wear. The platelets of nanoclay dispersed throughout the polymer act as obstacles, blocking the polyester from becoming severely fragmented ${ }^{31}$.

Also, Figures 8 and 9 display two types of wear mechanisms viz., abrasive and adhesive wear. The chopping and ploughing of the surface by harder particles are referred to as abrasive wear. In adhesive wear, the material is transferred from one surface to another, adhesive bonds are formed, developed, and eventually broken. It is important to remember that wear is usually caused by a variety of mechanisms rather than by a single mechanism.

The worn-out surface of water-soaked specimens (Figures 8b and 9b) displays a more irregular/bumpy surface (adhesive wear) as compared to as-made specimens

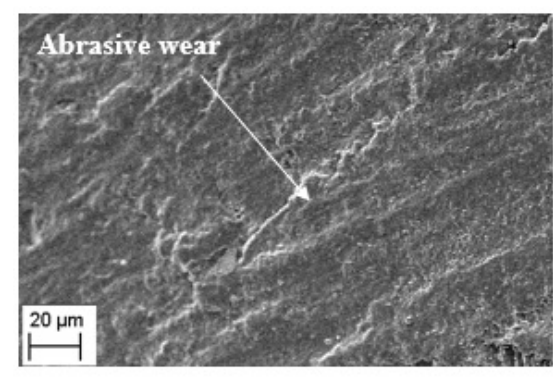

(a)

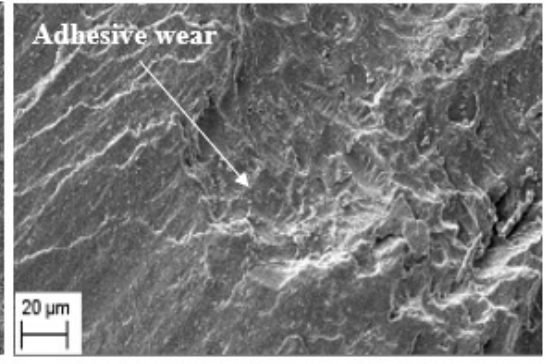

(b)

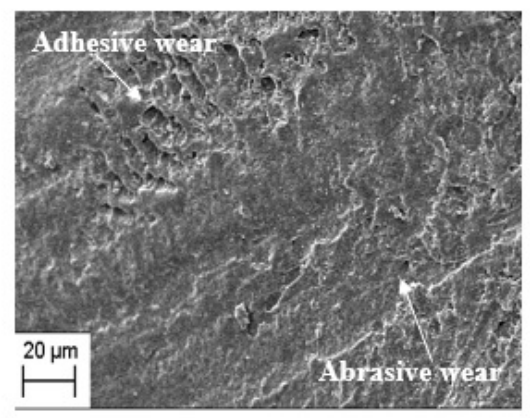

(c)

Figure 8. SEM images of the worn-out surface of pure polyester under different conditions (a) As-made (b) Water-soaked (c) Re-dried. 


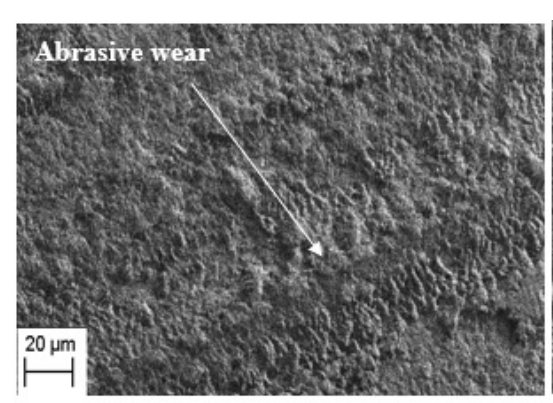

(a)

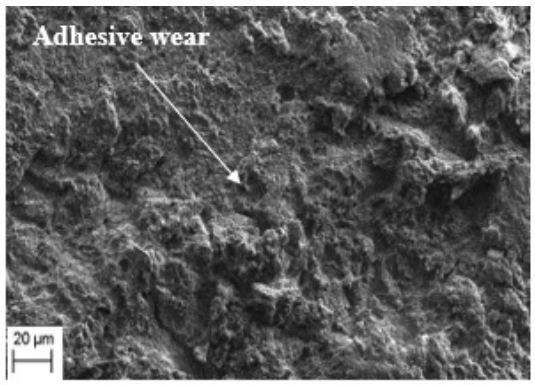

(b)

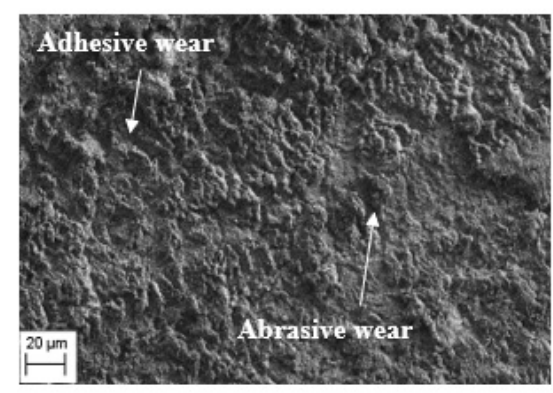

(c)

Figure 9. SEM images of the worn-out surface of NPNC (4 wt \%) under different conditions (a) As-made (b) Water-soaked (c) Re-dried.

(Figures 8a and 9a). Water-soaked specimens have not borne the frictional force; instead, they have broken more material because of swelling and plasticization. This is the main reason for more mass loss of specimens and the bumpy worn-out surface under water-soaked condition.

Re-dried specimen's worn-out surface (Figures 8c and 9c) shows lesser irregular/bumpy surface as compared to water-soaked specimens (Figures $8 b$ and 9b). Re-drying of the specimens leads to recovery from swelling and plasticization by removing the absorbed water. Also, re-drying does not fully nullify the effect of water-soaking. So, the re-dried specimen shows an irregular/bumpy surface as compared to as-made specimens (Figures $8 \mathrm{a}$ and 9a). Re-dried specimens worn-out surface displayed both wear mechanisms viz., abrasive and adhesive wear.

\section{Conclusion}

This research aimed to determine how water soaking and re-drying affect the mechanical and wear properties of pure polyester and NPNCs. Mechanical properties viz., tensile and flexural and wear property, (i.e., mass loss), are determined. The water-soaking and subsequent re-drying effects on mechanical and wear properties of pure polyester and NPNCs are investigated. The following consclusions are drawn.

1. Nanoclay addition reduces the total water uptake percentage of NPNCs by $5-11 \%$ in comparison to pure polyester at the saturation level.

2. Nanoclay addition enhances both tensile strength by $12-15 \%$ and flexural strength by $4-10 \%$ and reduces the overall effect of water soaking on NPNCs.
3. The tensile strength and modulus of pure polyester under water-soaked condition are decreased by 20 and $17 \%$, whereas, the tensile strength and modulus of NPNCs are declined by 16 and $15 \%$ at 2 wt. $\%$ nanoclay and 12 and $12 \%$ at 4 wt.\% nanoclay, respectively.

4. The flexural strength and modulus of pure polyester under water-soaked condition are decreased by 17 and $17 \%$, whereas, the flexural strength and modulus of NPNCs are declined by 14 and $9 \% 0$ at 2 wt. \% nanoclay and 11 and $8 \%$ at 4 wt.\% nanoclay, respectively.

5. The mechanical properties of re-dried specimens are recovered more than $90 \%$ of their original properties.

6. The mass loss of specimens reduces by 13 and $40 \%$ at 2 and 4 wt. $\%$ of nanoclay, respectively. In contrast, the water-soaking condition increased the mass loss of the specimens by 6 to $10 \%$.

7. Re-dried specimens have lesser mass loss than water-soaked specimens and greater mass loss than that on as-made specimens.

8. SEM images illustrate that the absorbed water can alter the fracture and worn-out surface. Also, SEM images are examined to correlate the reasons for the varying properties of the specimens under different conditions.

\section{References}

1. Saharudin MS, Atif R, Shyha I, Inam F. The degradation of mechanical properties in halloysite nanoclay-polyester 
nanocomposites exposed to diluted methanol. J Compos Mater. 2017;51(11):1653-64. http://dx.doi.org/10.1177/0021998316660178.

2. Shettar M, Hiremath P. Effect of seawater on mechanical properties of GFRP with cement as filler material for fishing boat application. Int J Appl Eng Res. 2015;10(19):40027-30.

3. Merah N, Mohamed O. Nanoclay and water uptake effects on mechanical properties of unsaturated polyester. J Nanomater. 2019;2019:1-11. http://dx.doi.org/10.1155/2019/8130419.

4. Chieruzzi M, Miliozzi A, Kenny JM. Effects of the nanoparticles on the thermal expansion and mechanical properties of unsaturated polyester/clay nanocomposites. Compos, Part A App1 Sci Manuf. 2013;45:44-8. http://dx.doi.org/10.1016/j. compositesa.2012.09.016.

5. Dogan A, Atas C. Variation of the mechanical properties of E-glass/epoxy composites subjected to hygrothermal aging. J Compos Mater. 2016;50(5):637-46. http://dx.doi. org/10.1177/0021998315580451.

6. Najafi M, Ansari R, Darvizeh A. Environmental effects on mechanical properties of glass/epoxy and fiber metal laminates, Part I: hygrothermal aging. Mech Adv Compos Struct. 2017;4(3):187-96. http://dx.doi.org/10.22075/MACS.2016.507.

7. Saharudin M, Atif R, Inam F. Effect of short-term water exposure on the mechanical properties of halloysite nanotube-multi layer graphene reinforced polyester nanocomposites. Polymers (Basel). 2017;9(12):27. http://dx.doi.org/10.3390/polym9010027.

8. Alamri H, Low IM. Effect of water absorption on the mechanical properties of nano-filler reinforced epoxy nanocomposites. Mater Des. 2012;42:214-22. http://dx.doi.org/10.1016/j. matdes.2012.05.060.

9. Saharudin MS, Atif R, Shyha I, Inam F. The degradation of mechanical properties in polymer nano-composites exposed to liquid media - a review. RSC Advances. 2016;6(2):1076-89. http://dx.doi.org/10.1039/C5RA22620A.

10. Guo F, Aryana S, Han Y, Jiao Y. A review of the synthesis and applications of polymer-nanoclay composites. Appl Sci (Basel). 2018;8(9):1696. http://dx.doi.org/10.3390/app8091696.

11. Domun N, Hadavinia H, Zhang T, Sainsbury T, Liaghat GH, Vahid S. Improving the fracture toughness and the strength of epoxy using nanomaterials - a review of the current status. Nanoscale. 2015;7(23):10294-329. http://dx.doi.org/10.1039/ C5NR01354B.

12. Shettar M, Kini A, Sharma S, Hiremath P. FRP-Nanoclay hybrid composites: a review. MSF. 2017;904:146-50.

13. Chan M, Lau K, Wong T, Ho M, Hui D. Mechanism of reinforcement in a nanoclay/polymer composite. Compos, Part B Eng. 2011;42(6):1708-12. http://dx.doi.org/10.1016/j. compositesb.2011.03.011.

14. Shettar M, Doshi M, Rawat AK. Study on mechanical properties and water uptake of polyester-nanoclay nanocomposite and analysis of wear property using RSM. J Mater Res Technol. 2021;14:1618-29. http://dx.doi.org/10.1016/j.jmrt.2021.07.034.

15. Nemati Giv A, Rastegar S, Özcan M. Influence of nanoclays on water uptake and flexural strength of glass-polyester composites. J Appl Biomater Funct Mater. 2020;18:228080002093018. http://dx.doi.org/10.1177/2280800020930180.

16. Hegde RR, Bhat GS, Deshpande B. Morphology and properties of nylon 6 blown films reinforced with different weight percentage of nanoclay additives. Int J Polym Sci. 2012;2012:1-14. http:// dx.doi.org/10.1155/2012/959035.
17. ASTM. American Society for Testing and Materials. ASTM D638-14: standard test method for tensile properties of plastics. West Conshohocken: ASTM; 2017.

18. ASTM. American Society for Testing and Materials. ASTM D790-10: standard test methods for flexural properties of unreinforced and reinforced plastics and electrical insulating materials. West Conshohocken: ASTM; 2016.

19. ASTM. American Society for Testing and Materials. AASTM D570-98: standard test method for water absorption of plastics. West Conshohocken: ASTM; 2018.

20. ASTM. American Society for Testing and Materials. ASTM G99-17: standard test method for wear testing with a pin-ondisk apparatus. West Conshohocken: ASTM; 2017.

21. Mohammed AA, Issa TT. The water absorption effect on the hardness of composites polyester. 2016;1727:020016. http:// dx.doi.org/10.1063/1.4945971.

22. Mohan TP, Velmurugan R, Kanny K. Damping characteristics of nanoclay filled hybrid laminates during medium velocity impact. Compos, Part B Eng. 2015;82:178-89. http://dx.doi. org/10.1016/j.compositesb.2015.08.016.

23. Krushnamurty K, Srikanth I, Rangababu B, Majee SK, Bauri R, Subrahmanyam C. Effect of nanoclay on the toughness of epoxy and mechanical, impact properties of e-glass-epoxy composites. Adv Mater Lett. 2015;6(8):684-9. http://dx.doi. org/10.5185/amlett.2015.5817.

24. Rafiq A, Merah N. Nanoclay enhancement of flexural properties and water uptake resistance of glass fiber-reinforced epoxy composites at different temperatures. J Compos Mater. 2019;53(2):143-54. http://dx.doi.org/10.1177/0021998318781220.

25. Saxena D, Soundararajan N, Katiyar V, Rana D, Maiti P. Structural, mechanical, and gas barrier properties of poly(ethylene terephthalate) nanohybrid using nanotalc. J Appl Polym Sci. 2020;137(27):48607. http://dx.doi.org/10.1002/app.48607.

26. Kusmono, Hestiawan H, Jamasri. The water absorption, mechanical and thermal properties of chemically treated woven fan palm reinforced polyester composites. J Mater Res Technol. 2020;9(3):4410-20. http://dx.doi.org/10.1016/j. jmrt.2020.02.065.</jrn>

27. Hamim SU, Singh RP. Effect of hygrothermal aging on the mechanical properties of fluorinated and nonfluorinated clayepoxy nanocomposites. Int Sch Res Notices. 2014;2014:1-13. http://dx.doi.org/10.1155/2014/489453.

28. Salim MS, Ariawan D, Ahmad Rasyid MF, Mat Taib R, Ahmad Thirmizir MZ, Mohd Ishak ZA. Accelerated weathering and water absorption behavior of Kenaf fiber reinforced acrylic based polyester composites. Front Mater. 2020;7. http://dx.doi. org/10.3389/fmats.2020.00026.

29. Hu Y, Ji W-M, Zhang L-W. Water-induced damage revolution of the carbon nanotube reinforced poly (methyl methacrylate) composites. Compos, Part A Appl Sci Manuf. 2020;136:105954. http://dx.doi.org/10.1016/j.compositesa.2020.105954.

30. Bera T, Mula S, Ray PK, Ray BC. Effects of thermal shocks and thermal spikes on hygrothermal behavior of glass: polyester composites. J Reinf Plast Compos. 2007;26(7):725-38. http:// dx.doi.org/10.1177/0731684409076732.

31. Jawahar P, Gnanamoorthy R, Balasubramanian M. Tribological behaviour of clay - thermoset polyester nanocomposites. Wear. 2006;261(7-8):835-40. http://dx.doi.org/10.1016/j. wear.2006.01.010. 